\title{
Assessment of the Reliability and Validity of Student-Lecturer Evaluation Questionnaire: A Case of North West University
}

\author{
Volition TIhalitshi Montshiwa
}

North West University, RSA

Email:Volition.Montshiwa@nwu.ac.za

\section{Ntebogang Dinah Moroke (Ph.D)}

North West University, RSA

Email: Ntebo.Moroke@nwu.ac.za

\author{
Doi:10.5901/mjss.2014.v5n14p352
}

\begin{abstract}
The study assessed the reliability and the validity of student-lecturer evaluation questionnaire used at the North West University in South Africa. The questionnaire was first used during the second semester of the year 2011 and was distributed to all students registered and present for lectures for piloting. This tool has not been tested for statistical significance before it could be implemented. It was however circulated on round robin to academics across the University for their inputs before it could be finalised. A total of 442 questionnaires distributed to students on a particular day of the year 2013 was analysed using Statistical Analysis Software version 9.3. Preliminary data analysis results provided enough evidence to conclude that the selected sample was adequate with the correlation matrix confirming the appropriateness of factor analysis. Cronbach's alpha confirmed that individual and collective constructs in the questionnaire are reliable. Exploratory factor analysis results helped in rearranging the student-lecturer evaluation questionnaire collecting the 26 statements into four factors instead of the original five. The results obtained in this study will be presented to the academic development centre of the university and suggestions based on the findings about the questionnaire will also be given. The tool may also through the permission of the university be recommended to schools in the area.
\end{abstract}

Keywords: Student Lecturer Evaluation questionnaire, Cronbach's alpha, Exploratory Factor Analysis, reliability, validity

\section{Introduction}

The student-lecturer evaluation (SLE) questionnaire or student evaluation of teaching (SET) as it is generally known is widely used in tertiary institutions around the world. The purpose of this tool is to collect feedback from students regarding their perceptions on factors such as the course, lecturers and the interaction between lecturers and the students. As cited by Woodsworth (2012), Watchel (1998: 154) asserts that "after nearly seven decades of research on the use of SET effectiveness, it is clear that the majority of researchers believe that student ratings are valid, reliable and worthwhile means of evaluating teaching".

Woodsworth (2012) argues, contrary to Watchel (1998)'s claim that literature report many conflicting findings and criticisms of SET are manifest throughout. This argument suggests that the research on this topic is not yet exhaustive. Very few of the SETs have been evaluated extensively in terms of potential biases, validity, and usefulness of feedback. What makes the SET instruments differ is the quality of items, the way the teaching effectiveness construct is operationalized, and specific dimensions that are included (Marsh and Dunkin, 1997). The authors also believe that the validity and usefulness of SET information depends upon the content and coverage of the items and the SET factors that they reflect. Poorly worded or inappropriate items may not provide useful information, while scores averaged across an illdefined assortment of items offer no basis for knowing what is being measured. Marsh and Dunkin (1997) emphasised that practically most instruments are based on a mixture of logical and pragmatic considerations, and this may occasionally include some psychometric evidence such as reliability or factor analysis. It is very important that the measurement of SET is valid and this therefore requires a continual interplay between theory, research and practice. This also requires careful attention to the components of teaching effectiveness that are to be measured. The usefulness of a SET program depends on more than having a well-designed instrument and this is an important starting point.

The main objective of this study is to evaluate the reliability and validity of the SLE questionnaire used at North 
West University (NWU). This instrument is currently being used by the university as the main source of feedback from students about their lecturer's concerning their attitudes towards the modules they facilitate, the ways they do facilitation, assess students, their work ethics and interaction with students among others. The information gathered using this instrument is used by the university in crucial decision-making such as tracking performance of every lecturer, decision for promotion, curriculum review and identification of expertise for each module. The feedback is also used for development of lecturers concerned. Lecturers are also allowed to use the information for personal development or skills improvement. The findings of the study may be used to ensure that the SLE questionnaire used at NWU is valid, reliable and that there is no bias. This may also assist other institutions using similar tools to ensure their authenticity and guard against biasedness. This study extends and bridges the gap in the literature on the on-going debate about the reliability and validity of the SLE or SET questionnaire.

\section{Literature Review}

Literature is evident that the validity and reliability of SLE has been the area of interest in most of the studies over the years. Most of the studies are in support of Woodsworth's (2012) view concerning research on the subject. Findings by different studies report on conflicting results and conclusions. Furthermore, reports by the most recent articles (Basow, Codos and Martin, 2013) and Johnson, Narayanan and Sawaya (2013) on the topic suggest that the evaluation of the validity and reliability of the SLE should still be exhausted also as Woodsworth suggested.

Some of the catalysts of the bias are associated with the use of SETs. Diverse class attributes, course attributes, and lecturers' and students' demographics were found to be some of the promoters of the external effects. As such, these attributes should be taken into consideration when evaluating the validity and reliability of the tool because their effects are found to cause bias the on the findings. However, most studies on the subject focused on the university population or students at large. Cohen (2005) used the data for the whole university and Sahin and Yilmaz (2011) used the data from students across Turkey. On the contrary, some studies such as those by Sok-Foon, Sze-Yin and Yin-Fah (2012) and Shevlin et al. (2000) narrowed their focus to school level and discipline level respectively.

The literature also showed that factor analysis is the most used statistical technique for evaluating the validity and reliability of the SLEs. Through it, the constructs defined by the items of the questionnaire were reported to be extractable. The items which are not making a significant contribution to the definition of constructs or factors of teaching effectiveness are often excluded from the tool. This leads to the improvement of the SLE by including the relevant items only, hence improving the validity of questionnaire items. The most common constructs in literature are related to the course, the teacher and the interaction between the two.

Literature also revealed the frequent usage of Exploratory Factor Analysis (EFA) over Confirmatory Factor Analysis (CFA) but there have been criticisms about these techniques. Some of the proponents of Confirmatory Factor Analysis (CFA) such as Martínez-Gómez et al. (2011) argue that the binomial EFA and Cronbach's alpha tests are unsatisfactory to evaluate the reliability and validity of the SLE questionnaire. They further point out the shortcoming of Cronbach's alpha as it assumes the construct unidimensionality instead of ensuring it.

Schimitt (2011) suggest the application of EFA as it shows which construct is most likely without the theoretical a priori. Other researchers such as Sahin and Yilmaz (2011) used CFA subsequent to EFA to confirm the outcomes of EFA. However, Little (2013) opposes this practice by pointing out that the poor application of either of the two may influence the disagreement of the outcomes of such methods. As such, the current study only adopts the EFA approach in assessing the validity of the SLE questionnaire.

Construct reliability has mostly been assessed using Cronbach's alpha and most of literature that was reviewed in this chapter revealed that the SETs are reliable. It is worth noting that reliability in the context of this study refers to internal consistency. Supino and Borer (2012) define internal consistency as the assessment of the estimates of the homogeneity of the items in a scale that are intended to measure the same construct. The authors qualified this method as suitable for likert scaled variables and this is one of the reasons why it was used in this study to assess the reliability of the said questionnaire.

\section{Objectives of the Study}

The specific objectives of this study are to:

- Examine the factor structure of NWU SLE questionnaire.

- Assess the validity of NWU SLE questionnaire.

- Determine the reliability of NWU SLE questionnaire. 
- Use the findings of this study in formulating suggestions to Academic Development Centre (ADC) of the university about this SLE questionnaire

\section{Method}

\subsection{The Instrument}

The instrument being evaluated in this study is a 26 item Optical Character Recognition (OCR) based SLE questionnaire. It was first used by the university in the second semester of 2011 for the purpose of a pilot study. The university used to capture the collected data manually in Microsoft Excel. Presently, the OCR technology enables the questionnaire (with same items and sections) to be scanned and directly exported to Microsoft Excel. This data capturing approach improves accuracy and it is time efficient. The questionnaire was used to elicit perceptions of students about their lectures with special reference to their preparedness for lectures, presentation of lectures, assessment of students, relations with them and subject knowledge by lecturers. One of the assumptions of factor analysis concerns the type of variables analysed. Field (2013) suggest the use of interval scaled variables. A likert scale is assumed to be interval according to Ratray and Jones (2005), although the item scores are discreet values. Coussement, Demoulin and Charry (2011) support this view and vouch that previous studies showed that such a practise does not necessarily produce unreliable results. Each category in the SLE questionnaire is a four point likert scale with options ordered as 1-strongly disagree, 2-disagree, 3agree and 4-strongly agree. Table 1 summarises the respective segments of the questionnaire. Ethical approval for the study was obtained from the research ethics committee of the NWU.

Table 1: Summary of the NWU SLE questionnaire items ${ }^{1}$

\begin{tabular}{|l|c|l|}
\hline \multicolumn{1}{|c|}{ Section } & $\begin{array}{c}\text { Item/ } \\
\text { Questions }\end{array}$ & \multicolumn{1}{c|}{ Description } \\
\hline 1. Preparation & $1-3$ & This section comprise questions used to measure how well the lecturer prepares for the lecture \\
\hline 2. Presentation & $4-11$ & $\begin{array}{l}\text { Feedback on how well the lecturer present the lecture such as utilisation of audio-visual facilities } \\
\text { and the level of language they use }\end{array}$ \\
\hline $\begin{array}{l}\text { 3. Relationship with } \\
\text { students }\end{array}$ & $12-14$ & $\begin{array}{l}\text { The questions are related to how well the lecturer interacts with students such as approachability } \\
\text { and availability for consultation }\end{array}$ \\
\hline 4. Assessment & $15-19$ & $\begin{array}{l}\text { These are questions related to how well the lecturer assesses the tests, assignment and how } \\
\text { satisfied the student is with the feedback }\end{array}$ \\
\hline 5. Subject content & $20-26$ & The questions are related to how well the lecturer delivers the course content to students \\
\hline
\end{tabular}

\subsection{Data}

Questionnaires were distributed to statistics undergraduate students towards the end of the academic year of 2013. The collection of data was reinforced by a designated member of the ADC who explained to students the purpose of the questionnaire and also helped in administering it. In order to encourage honest responses to a somewhat sensitive subject, students were assured that their anonymity would be observed and that the results of the study would be used for research purposes only. Questionnaires were distributed to 442 students who availed themselves for lectures of the nine modules in that particular day. A return rate of about $68 \%$ was achieved.

\subsection{Data analysis}

Data analysis was executed with respect to the objectives set for this study. Statistical Analysis Software (SAS) version 9.3 was used to execute the analysis. This section comprise of two categories one for preliminary and another for the actual analyses with EFA. On the preliminary analysis, the sample used was firstly checked for adequacy using the Keiser Meyer Olkin (KMO to ensure that the sample chosen is in accordance with the requirements for factor analysis. Secondly, to estimate internal consistency, also called reliability, Cronbach's alpha coefficients was calculated for scores yielded by the SLE questionnaire for each of the items and in overall. Correlation matrix was calculated to examine any statistically significant relationships among the items in the third step. The last step used an exploratory factor analysis (EFA) using principal factor analysis to explore the underlying structure of the SLE questionnaire of the NWU.

\footnotetext{
${ }^{1}$ For a more detailed SLE questionnaire refer to Appendix
} 


\subsubsection{Measure of sample adequacy}

Hinkin (2009) emphasise that the use of a large sample in factor analyses assists in obtaining stable standard errors and also assures that factor loadings are accurate reflections of the actual population. This view is emphasised by Costello and Osborne (2005), Field (2013) and Tabachnick and Fidell (2007). A common rule of thumb is to use at least 10 to 15 cases per item. The recommended criteria to determine the sample size by Comrey and Lee (1992) as cited in Tabachnick and Fidel (2012), is as follows; 50 is very poor, 100 is poor, 200 is fair, 300 is good, 500 is very good and at least 1000 is excellent. Tabachnick and Fidell (2007) advised that due to the reduced reliability of correlation coefficients between the variables as a result of small samples, the sample size acceptable for a reliable underlying construct should range from 200 to 300 and this is agreeable with Comrey and Lee (1992). The sample used for this study consists of 442 observations and as such meet the minimum requirements for factor analysis. Statistical determination of sample sufficiency was confirmed with Kaiser-Meyer Oklin (KMO) statistic as adopted from Pett, Lackey \& Sullivan (2003). KMO can as highlighted by Field (2013) signal in advance if the sample size is large enough to reliably extract the factors. This statistics is calculated using the formula:

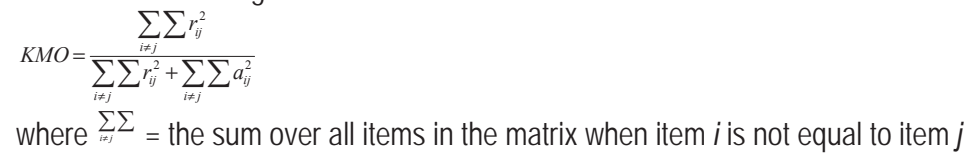

$r_{i j}=$ the Pearson's correlation between $i$ and $j$ and ${ }^{a_{i j}}=$ the partial correlation coefficient between $i$ and $j$ and $0 \leq K M O \leq 1$. Pett et al. (2003) recommended the following criteria to decide on the adequateness; less than 0.6 is mediocre, miserable or unacceptable, in the $0.7 \mathrm{~s}$ is middle, in the $80 \mathrm{~s}$ is meritorious and above the $0.9 \mathrm{~s}$ is marvellous sampling adequacy. The study used the Bartlett's test of sphericity to test for the appropriateness of the sample from the population and also the suitability of factor analysis. Alese and Owayemi (2004) suggest this test for the adequacy of the sample as a true representation of the population under study.

\subsubsection{Reliability test}

This study uses Cronbach's alpha to estimate internal consistency reliability for SLE questionnaires. The first step for testing for reliability of the items of the SLE questionnaire was to compute the Cronbach's alpha based on the following formula adopted from Rao and Sinharay (2006);

$$
\alpha=\frac{k}{k-1}\left(1-\frac{\sum s_{i}^{2}}{s_{t}^{2}}\right)
$$

where $k=26$ (the number of items of the SLE questionnaire), $s_{i}^{2}$ refers to the variance of item $i$ and $s_{t}^{2}$ is the total variance. As suggested by Byrne, Shavelson, and Muthen (1989), the items for each question have to represent a single concept. This suggestion is supported by among others Blaha, Merydith, Wallbrown and Dowd (2001) and Diamantopoulos and Siguaw (2006). Cronbach's coefficient alpha ranges from 0 to 1, and the values closer to 0 imply that the items do not measure the same construct and values closer to 1 provides an opposite implication. Cronbach and Shavelson (2004) use the following rules of thumb to describe Cronbach's alpha $a: \geq 0.9$ is excellent, $0.8 \leq a<0.9$ is good, $0.7 \leq a<0.8$ is acceptable, $0.6 \leq a<0.7$ is questionable, $0.5 \leq a<0.6$ is poor and $a<0.5$ as unacceptable.

\subsubsection{The Factor Model}

This study uses EFA to help achieve the objectives. Glynn and Woodside (2009) suggested principal factor analysis (PFA) as it does not distort the original items of the questionnaires. This method also yields factor scores that have the same correlation coefficients as the rotated factors. One other advantage of this method is that it does not unduly capitalise on sampling error as the price for estimating measuring error (Thompson and Daniel, 1996). The purpose of EFA is the description, if possible, the covariance relationships among many variables in terms of a few underlying, but unobservable, random quantities called factors as defined by Johnson and Wichern (2007). On the other hand Rencher (2003) refers to this technique as one-sample procedure for applications to data with groups; that is, assuming a random sample $\left(y_{1}, y_{2}, \ldots, y_{n}\right)$ from a homogeneous population with mean vector ${ }^{\mu}$ and covariance matrix $\Sigma$. An assumption that each variable $\left(y_{1}, y_{2}, \ldots, y_{p}\right)$ in the random vector $y$ is a linear function of $m$ factors $\left(f_{1}, f_{2}, \ldots f_{m}\right)$ with the accompanying error term to account for that part of the variable that is unique holds. The following model shows linear combination of factors: 


$$
\begin{aligned}
& y_{1}=\mu_{1}+\lambda_{11} f_{1}+\lambda_{12} f_{2}+\ldots+\lambda_{1 m} f_{m}+\varepsilon_{1} \\
& y_{2}=\mu_{2}+\lambda_{21} f_{1}+\lambda_{22} f_{2}+\ldots+\lambda_{2 m} f_{m}+\varepsilon_{2} \\
& y_{p}=\mu_{p}+\lambda_{p 1} f_{1}+\lambda_{p 2} f_{2}+\ldots+\lambda_{p m} f_{m}+\varepsilon_{p}
\end{aligned}
$$

The model in (1) for the $p$ variables combined in the single matrix expression as:

$$
y=\mu+\Lambda f+\varepsilon
$$

$$
\begin{aligned}
& \text { where } y=\left(y_{1}, y_{2}, \ldots, y_{p}\right)^{\prime}, \mu=\left(\mu_{1}, \mu_{2}, \ldots, \mu_{p}\right)^{\prime}, f=\left(f_{1}, f_{2}, \ldots, f_{m}\right)^{\prime}, \varepsilon=\left(\varepsilon_{1}, \varepsilon_{2}, \ldots, \varepsilon_{p}\right)^{\prime} \text { and } \\
& \Lambda=\left[\begin{array}{cccc}
\lambda_{11} & \lambda_{12} & \ldots & \lambda_{1 m} \\
\lambda_{21} & \lambda_{22} & \ldots & \lambda_{2 m} \\
\vdots & \vdots & \ddots & \vdots \\
\lambda_{p 1} & \lambda_{p 2} & \ldots & \lambda_{p m}
\end{array}\right] \text {. }
\end{aligned}
$$

The factors of (3) are unobservable making this model different from the multivariate regression model. The error terms are independent of each other such that $E\left(\varepsilon_{i}\right)=0$ and $\operatorname{var}\left(\varepsilon_{i}\right)=\sigma_{i}^{2}$. The factors ${ }^{f_{i}}$ are independent of one another and also do not depend on the error terms such that $E\left(f_{i}\right)=0$ and $\operatorname{var}\left(f_{i}\right)=1$. The sample variance of a variable $y_{i}$ is defined by:

$$
\begin{aligned}
\operatorname{var}\left(y_{i}\right) & =\left(\lambda_{i 1}^{2}+\lambda_{i 2}^{2}+\ldots+\lambda_{i m}^{2}\right)+\psi_{i} \\
& =\underbrace{h_{i}^{2}}_{\text {communality }}+\underbrace{\psi_{i}}_{\text {unique evariance }}
\end{aligned}
$$

where

$$
\text { communality }=h_{i}^{2}=\lambda_{i 1}^{2}+\lambda_{i 2}^{2}+\ldots+\lambda_{i m}^{2}
$$

Communality is the variance in observed variables accounted for by common factors as defined by Hatcher (2003). The total variance may be expressed as:

$$
\operatorname{Var}\left(y_{i}\right)=c_{i}^{2}+h_{i}^{2}+r_{i}^{2}
$$

If $m$ factors were perfect predictors of ${ }^{y_{i}}$, then $\varepsilon_{i}=0$ and ${ }^{\sigma_{i}^{2}}=1$. A large communality value signifies a strong influence by the underlying factors.

\subsubsection{Correlation matrix}

Prior to conducting factor analysis, one other step is the generation of correlation. An indication of whether the variables are highly or lowly correlated with other variables can be obtained from this matrix (Field, 2013 and Tabachnick and Fidel, 2012). The factors are expected to be uncorrelated with the variance in (3). The covariance of any two variables ${ }^{y_{i}}$ and $y_{j}$ is written as:

$$
\operatorname{cov}\left(y_{i}, y_{j}\right)=\sigma_{12}=\lambda_{11} \lambda_{21}+\lambda_{12} \lambda_{22}
$$

with $\left(\lambda_{1}, \lambda_{21}\right)$ being the first row and $\left(\lambda_{12}, \lambda_{22}\right)$ is the second row of equation (5). If $y_{1}$ and $y_{2}$ have a pact in common, they will have similar loadings on the common factors $f_{1}$ and $f_{2}$, i.e. $\left(\lambda_{11}, \lambda_{21}\right)$ will be similar to $\left(\lambda_{12}, \lambda_{22}\right)$. On the other hand, if $y_{1}$ and $y_{2}$ have little in common, then their loadings $\lambda_{11}$ and $\lambda_{21}$ on $f_{1}$ will be different and their loadings $\lambda_{12}$ and $\lambda_{22}$ on $f_{2}$ will likewise differ. In this case the products $\left(\lambda_{11}, \lambda_{21}\right)$ and $\left(\lambda_{12}, \lambda_{22}\right)$ will tend to be small. Equation (6) follows the fact that $\operatorname{cov}\left(f_{i}, f_{j}\right)=0, \operatorname{var}\left(f_{i}\right)=1$ and $E\left(\varepsilon_{i}, \mathcal{E}_{j}\right)=0$. Correlations as high as 0.8 make it impossible to determine the unique contribution to a factor. Consequently, correlations as low as 0.3 may probably imply that the variable does not measure the same underlying construct as other variables (Field, 2013). Alternatively the observed p-value is compared with the significance level to decide on the factorability of correlation matrix. Munro (2005) suggests a significant $p$-value to conclude that the correlation matrix is not an identity and that it is factorable.

\subsubsection{The number of factors to be extracted}

One other requirement of EFA is deciding of the number of factors to be extracted. Antony and Barlow (2011) warned that if very few factors are wrongfully retained, the complete structure of the construct is not revealed and the structural 
validity is compromised. Furthermore, if on the contrary too many factors are retained then interpretability becomes cumbersome. As such Fabrigar and Wegener (2012) recommend that researchers must try to balance parsimony and plausibility when it comes to selecting the number of factors to include in a model. This study uses the scree test by (Cattell, 1978) to identify the number of factors to be extracted. The principle for using this method is to find the spot on the plot which makes an elbow. This test is more accurate than the eigenvalues-greater-than-one criterion when both are tested on artificially generated sample data (Zwick and Velicer, 1986). Stevens (2002) also recommends this criterion as it retains fewer factors.

\subsubsection{Initial Factor Extraction}

The extraction of factors requires the calculation of the eigenvalues of the matrix where the number of positive eigenvalues determines the number of constructs needed to represent set of scores without any loss of information (Rietveld and Van Hout, 1993). The parameters in a factor analysis model include the loadings and the communalities. The technique for extracting factors attempts to take out as much common variance as possible in the first factor. Subsequent factors are, in turn, intended to account for the maximum amount of the remaining common variance until, hopefully, no common variance remains (Suhr, 2009).

Let covariance matrix $\Sigma$ have eigenvalue - eigenvector pairs ${ }^{\left(\lambda_{i}, e_{i}\right)}$, with $\lambda_{1} \geq \lambda_{2} \geq \ldots \lambda_{p}$ then the spectral decomposition says:

$$
\sum=\lambda_{1} e_{1} e_{1}^{\prime}+\lambda_{2} e_{2} e_{2}^{\prime}+\ldots+\lambda_{p} e_{p} e_{p}^{\prime}=\left[\begin{array}{lll}
\sqrt{\lambda_{1}} e_{1} & \sqrt{\lambda_{2}} e_{2} \ldots & \sqrt{\lambda_{p}} e_{p}
\end{array}\left[\begin{array}{c}
\sqrt{\lambda_{1}} e_{1}^{\prime} \\
\vdots \\
\sqrt{\lambda_{p}} e_{p}^{\prime}
\end{array}\right],\right.
$$

where $\lambda_{1 \geq} \lambda_{2} \cdots \lambda_{m} \geq 0$

So, if $L=\left\lfloor\sqrt{\lambda_{1}} e_{1}: \sqrt{\lambda_{2}} e_{2} \vdots \ldots \vdots \sqrt{\lambda_{m}} e_{m}\right\rfloor$, then $\sum=L L^{\prime}$.

According to Rencher (2003), the preferred model is the one in which the number of factors $(m)$ is less than the number of variables $(p)$ since this model explains the covariance structure in terms of the factors.

$$
\begin{aligned}
& \therefore \text { For }(m<p) \text { model: } \\
& \widetilde{L}=\left\lfloor\sqrt{\widetilde{\lambda}_{1}} \widetilde{e}_{1} \vdots \sqrt{\widetilde{\lambda}_{2}} \widetilde{e}_{2} \vdots \ldots \vdots \sqrt{\widetilde{\lambda}_{m}} \widetilde{e}_{m}\right\rfloor \text {, }
\end{aligned}
$$

Allowing for specific factors, the approximation becomes:

$$
=L \approx L L^{\prime}+\Psi
$$

$$
=\left[\begin{array}{lll}
\lambda_{1} e_{1} & \sqrt{\lambda_{2}} e_{2} \vdots \ldots \vdots & \sqrt{\lambda_{p}} e_{p}
\end{array}\left[\begin{array}{c}
\sqrt{\lambda_{1}} e_{1}^{\prime} \\
\sqrt{\lambda_{2}} e_{2} \\
\sqrt{\lambda_{3}} e_{3} \\
\sqrt{\lambda_{p}} e_{p}^{\prime}
\end{array}\right]+\left[\begin{array}{ccc}
\Psi_{1} & 0 \ldots & 0 \\
\vdots & \Psi_{2} & \vdots \\
0 & \cdots & \ddots \Psi_{p}
\end{array}\right]\right. \text {, }
$$

Where:

$$
\begin{aligned}
& \Psi_{j}=\delta_{i i}-\sum l_{i j}^{2} \text { for } i=1,2, \ldots p \\
& \text { and } S=\widetilde{L} \widetilde{L}^{\prime}+\widetilde{\Psi} \\
& \widetilde{\Psi}=\operatorname{Diag}\left(S-\widetilde{L} \widetilde{L}^{\prime}\right)
\end{aligned}
$$

The significance of factor loadings in the factor matrix is determined using the significance scale founded by Stevens (1992) and recommended by Field (2013). The scale shows that despite the commonly used criterion of using a cut-off point of absolute correlations of 0.3 , the minimum loading value required for a factor to be significant is dependent on the sample size. Specifically, the larger the sample size the smaller the cut-off loading value recommended for significant factor loadings. Stevens (1992) suggested the following criteria to select significant loadings; loading of 0.722 is significant if $n=50,0.512$ if $n=100,0.364$ if $n=2000.298$ if $n=300,0.21$ if $n=600$ and 0.16 if $n=1000$. The sample used in this study comprises of 442 observations and as a result loadings in excess of 0.3 are interpreted. Hatcher (2003) recommended a factor with at least 3 significant loadings.

\subsubsection{Factor rotation}

Unrotated factor loadings achieve the objective of data reduction but do not provide the results that are easy to work with 
(Bryant and Yarnold, 1995). The factor solution is orthogonally rotated in this study using the orthogonal rotation to help get better results of the final solution that are easily interpretable. This decision is supported by Weiner, Schinka and Velicer (2012) and Pett et al. (2003) who recommend this method as it maximally differentiates the factors from one another and it simultaneously simplifies the factors and the variables. Lewis-Beck, Bryman, and Liao (2004) suggest that an orthogonal rotation must be specified by a rotation matrix, where the rows stand for the original factors and the columns for the new (rotated) factors. The estimated loading matrix $\hat{\Lambda}$ can likewise be rotated to obtain:

$$
\hat{\Lambda}^{*}=\hat{\Lambda} T \text {, }
$$
before:

where $T$ is orthogonal. Since $T^{\prime} T=I$, the rotated loadings provide the same estimate of the covariance matrix as

$$
S \cong \hat{\Lambda}^{*} \hat{\Lambda}^{\prime}+\hat{\Psi}=\hat{\Lambda} T T^{\prime} \hat{\Lambda}^{\prime}+\hat{\Psi}=\hat{\Lambda} \hat{\Lambda}^{\prime}+\hat{\Psi} .
$$

The orthogonal rotation preserves communalities. This is because the rows of $\hat{\Lambda}$ are rotated, and the distance to the origin is unchanged, which by (7), is the communality. However, the variance accounted for by each factor will change, as will the corresponding proportion.

\section{Empirical Results}

\subsection{Prerequisites}

The overall sample used in this study conforms to sample size requirements by authors cited. A total of 26 items was used each containing 442 observations. This is also confirmed by the overall KMO $=0.972$ and for individual items in SLE questionnaire in Table 2 which are all in the 0.90s. It is therefore concluded that the sample used is marvellous according to Pett et al. (2003). All the variables are therefore considered in factor analysis.

Table 2a: Sample adequacy

\begin{tabular}{|c|c|c|c|c|c|c|c|c|c|c|c|c|}
\hline \multicolumn{10}{|c|}{ Item Kaiser's Measure of Sampling Adequacy } \\
\hline Q1 & Q2 & Q3 & Q4 & Q5 & Q6 & Q7 & Q8 & Q9 & Q10 & Q11 & Q12 & Q13 \\
\hline 0.957 & 0.959 & 0.971 & 0.981 & 0.975 & 0.971 & 0.974 & 0.977 & 0.955 & 0.956 & 0.969 & 0.957 & 0.970 \\
\hline Q14 & Q15 & Q16 & Q17 & Q18 & Q19 & Q20 & Q21 & Q22 & Q23 & Q24 & Q25 & Q26 \\
\hline 0.978 & 0.975 & 0.980 & 0.977 & 0.981 & 0.981 & 0.975 & 0.973 & 0.9696 & 0.974 & 0.973 & 0.977 & 0.9773 \\
\hline
\end{tabular}

Table 2b: KMO and Bartlett's Test results

\begin{tabular}{|l|r|c|}
\hline \multicolumn{2}{|c|}{ Kaiser-Meyer-Olkin Measure of Sampling Adequacy } & 0.972 \\
\hline \multirow{3}{*}{ Bartlett's Test of Sphericity } & Approx. Chi-Square & 9555.546 \\
\cline { 2 - 3 } & $\mathrm{df}$ & 325 \\
\cline { 2 - 3 } & Sig. & 0.000 \\
\hline
\end{tabular}

The observed p-value corresponding to the Bartlett's test of sphericity is significant at $5 \%$ level of significance; hence the null hypothesis that the correlation matrix is an identity matrix was rejected. As such, adopting Munro's (2005) criterion, a conclusion is reached that at least one common factor may be present. These finding concur with suggestions by Tabachnick and Fidel (2012).

Measure of internal reliability, Cronbach's alpha of the SLE questionnaire results are presented in Table 3. Individual item coefficients together with the overall alpha all exceed 0.9 implying that the entire items used in the SLE questionnaire are consistent and reliable. The internal consistency score for each of the five factors; preparation $(\alpha=0.783)$ is acceptable, relationship with students $(\alpha=0.807)$ and assessment $(\alpha=0.871)$ is good, with presentation $(\alpha=0.924)$ and subject content $(\alpha=0.947)$ as being excellent. The findings are in accordance with suggestions by Byrne et al. (1989), Blaha et al. (2001) and others. Next, we apply exploratory factor analyses to assess the validity of the questionnaire.

Table 3a: Overall Cronbach's alpha

\begin{tabular}{|c|c|}
\hline Variables & Cronbach's coefficient Alpha \\
\hline Raw & 0.971 \\
\hline Standardized & 0.971 \\
\hline
\end{tabular}


Table 3b: Cronbach's alpha for constructs and when the item is deleted

\begin{tabular}{|c|c|c|}
\hline Item: The lecturer is... & Alpha & Construct \\
\hline Is punctual for class & 0.971 & \multirow{3}{*}{0.783} \\
\hline Plans \& prepares for class thoroughly & 0.970 & \\
\hline Makes use of the study guide to prepare lessons & 0.971 & \\
\hline Uses a level of language that I can understand & 0.970 & \multirow{8}{*}{0.871} \\
\hline Presents stimulating lectures & 0.969 & \\
\hline Presents lecturers that I can learn from & 0.969 & \\
\hline States outcomes of each contact session & $\overline{0.969}$ & \\
\hline Makes use of multimedia support learning/ makes effective use of visual aids & 0.970 & \\
\hline Encourages us to work together during lecturers & 0.970 & \\
\hline Encourages me to participate in the class discussions & 0.970 & \\
\hline Encourages me to ask questions/ provides opportunities for assessment during class & 0.969 & \\
\hline Is friendly towards individual students & 0.971 & \multirow{3}{*}{0.807} \\
\hline Is approachable & 0.970 & \\
\hline Is available for consultation during consultation hours & 0.971 & \\
\hline Explains how outcomes will be assessed & 0.969 & \multirow{5}{*}{0.924} \\
\hline Gives feedback on tests and tasks within a reasonable time & 0.970 & \\
\hline Assesses assignments and projects fairly & 0.970 & \\
\hline Bases assessment on learning outcomes & 0.970 & \\
\hline Refers students to learning support when they achieve poorly & 0.970 & \\
\hline Explains the relevance of all concepts and theories & 0.969 & \multirow{7}{*}{0.947} \\
\hline Explains the connection between theory and practice & 0.969 & \\
\hline Refers to relevant and recent developments in the subject & 0.969 & \\
\hline Integrates all the learning activities/ experiences in my study guide & 0.969 & \\
\hline Makes the link between study units clear and logical & 0.969 & \\
\hline Prescribes a fair volume of study material & 0.969 & \\
\hline Presents study material in an organised manner & 0.969 & \\
\hline
\end{tabular}

\subsection{Factor analysis results}

Correlation matrix: The heart of factor analyses lies on the correlation matrix. A correlation matrix of the items in the SLE questionnaire was generated using factor analysis procedure. The aim is to check the degree of correlation between the variables. An examination of this matrix shows that all the correlation coefficients are in excess of 0.3 and none exceeds 0.8. This implies that neither of the variables is highly nor lowly correlated with others allowing the use of the chosen factor analyses methods with all the variables included.

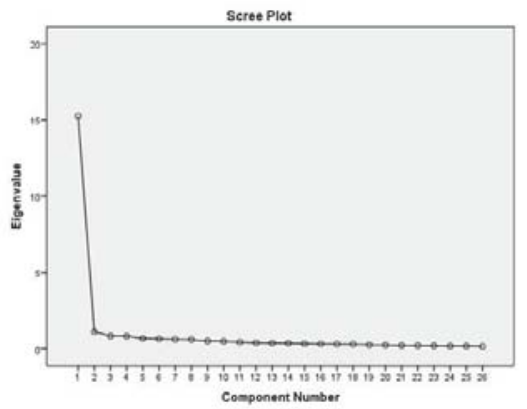

Figure 1: The scree plot

Number of factors: As demonstrated in Figure 1, a small proportion of a total of 26 items of the correlation matrix has a considerable eigenvalue of which many reach zero or even lower. The scree plot reveals a break point after the fourth suggesting a retention of four factors. The study therefore uses four factors to explain the twenty six items in the SLE 
questionnaire. All the factors with values after the breakpoint are eliminated. Having decided on the number of factors, the study continues to extract these factors and the results are summarised in Table 4.

Table 4: The Initial factor pattern

\begin{tabular}{|c|c|c|c|c|c|}
\hline No & Statement & Factor1 & Factor2 & Factor3 & Factor4 \\
\hline 1 & Is punctual for class & 0.645 & & & 0.448 \\
\hline 2 & Plans \& prepares for class thoroughly & 0.778 & & & 0.321 \\
\hline 3 & Makes use of the study guide to prepare lessons & 0.704 & & & \\
\hline 4 & Uses a level of language that I can understand & 0.729 & & & \\
\hline 5 & Presents stimulating lectures & 0.833 & & & \\
\hline 6 & Presents lecturers that I can learn from & 0.815 & & & \\
\hline 7 & States outcomes of each contact session & 0.791 & & & \\
\hline 8 & Makes use of multimedia support learning/ makes effective use of visual aids & 0.756 & & & \\
\hline 9 & Encourages us to work together during lecturers & 0.650 & 0.506 & & \\
\hline 10 & Encourages me to participate in the class discussions & 0.763 & 0.410 & & \\
\hline 11 & Encourages me to ask questions/ provides opportunities for assessment during class & 0.785 & 0.344 & & \\
\hline 12 & Is friendly towards individual students & 0.682 & & 0.346 & -0.349 \\
\hline 13 & Is approachable & 0.723 & & 0.318 & \\
\hline 14 & Is available for consultation during consultation hours & 0.665 & & 0.322 & \\
\hline 15 & Explains how outcomes will be assessed & 0.836 & & & \\
\hline 16 & Gives feedback on tests and tasks within a reasonable time & 0.729 & & & \\
\hline 17 & Assesses assignments and projects fairly & 0.735 & & & \\
\hline 18 & Bases assessment on learning outcomes & 0.769 & & & \\
\hline 19 & Refers students to learning support when they achieve poorly & 0.669 & & & \\
\hline 20 & Explains the relevance of all concepts and theories & 0.839 & & & \\
\hline 21 & Explains the connection between theory and practice & 0.815 & & & \\
\hline 22 & Refers to relevant and recent developments in the subject & 0.797 & & & \\
\hline 23 & Integrates all the learning activities/ experiences in my study guide & 0.838 & & & \\
\hline 24 & Makes the link between study units clear and logical & 0.856 & & & \\
\hline 25 & Prescribes a fair volume of study material & 0.809 & & & \\
\hline 26 & Presents study material in an organised manner & 0.829 & & & \\
\hline
\end{tabular}

Table 4 shows that all the 26 items are in favour of the first factor, lecturer's preparation. A factor loading with absolute value exceeding 0.3 was considered sufficiently high to assume a strong relationship between that variable and a corresponding factor. Also revealed is cross loadings per factors and a quiet number of insignificant loadings in other factors. This makes the interpretation of the pattern difficult. Factors are orthogonally rotated using the equamax rotation to fine tune the loadings on each factor thus simplifying the factor structure. Rotated factor loadings and the suggested names are presented in Table 5.

Table 5: Rotated Factor Loadings

\begin{tabular}{|c|c|c|c|c|c|}
\hline No & Statement & Factor1 & Factor2 & Factor3 & Factor4 \\
\hline \multicolumn{6}{|c|}{ Knowledge of Course Content } \\
\hline 21 & Explains the connection between theory and practice & 0.716 & & & \\
\hline 22 & Refers to relevant and recent developments in the subject & 0.697 & & & \\
\hline 20 & Explains the relevance of all concepts and theories & 0.669 & & & \\
\hline 19 & Refers students to learning support when they achieve poorly & 0.601 & & & \\
\hline 24 & Makes the link between study units clear and logical & 0.598 & & & \\
\hline 26 & Presents study material in an organised manner & 0.598 & & & \\
\hline 25 & Prescribes a fair volume of study material & 0.596 & & & \\
\hline 23 & Integrates all the learning activities/ experiences in my study guide & 0.593 & & & \\
\hline 15 & Explains how outcomes will be assessed & 0.534 & & & \\
\hline \multicolumn{6}{|c|}{ Preparation, Presentation and Assessment } \\
\hline 2 & Plans and prepares for class thoroughly & & 0.731 & & \\
\hline 1 & Is punctual for class & & 0.634 & & \\
\hline
\end{tabular}




\begin{tabular}{|c|c|c|c|c|}
\hline$\underline{5}$ & Presents lecturers that I can learn from & 0.579 & & \\
\hline 6 & States outcomes of each contact session & 0.565 & & \\
\hline 17 & Assesses assignments and projects fairly & 0.554 & & \\
\hline 18 & Bases assessment on learning outcomes & 0.549 & & \\
\hline 16 & Gives feedback on tests and tasks within a reasonable time & 0.527 & & \\
\hline 4 & Uses a level of language that I can understand & 0.519 & & \\
\hline 3 & Makes use of the study guide to prepare lessons & 0.499 & & \\
\hline 7 & States outcomes of each contact session & 0.461 & & \\
\hline \multicolumn{5}{|c|}{ Motivation and Encouragement of Students } \\
\hline 9 & Encourages us to work together during lecturers & & 0.825 & \\
\hline 10 & Encourages me to participate in the class discussions & & 0.796 & \\
\hline 11 & Encourages me to ask questions/ provides opportunities for assessment during class & & 0.673 & \\
\hline 8 & Makes use of multimedia support learning/ makes effective use of visual aids & & 0.532 & \\
\hline \multicolumn{5}{|c|}{ Relationship with Students } \\
\hline 12 & Is friendly towards individual students & & & 0.801 \\
\hline 13 & Is approachable & & & 0.748 \\
\hline 14 & Is available for consultation during consultation hours & & & 0.671 \\
\hline
\end{tabular}

After factor rotation, the significant factor loadings were distributed across all factors. The criterion of three significant loadings per factor was satisfied. The factor loadings were therefore found to be interpretable and this is in accordance with Hatcher's (2003) recommendation.

\section{Conclusions}

The empirical findings of this study showed that the 26 items of SLE questionnaire of the NWU are individually excellent and collectively more than acceptable. This proves the internal consistency of the items and constructs of this questionnaire. Presentation and subject content were found to be more reliable in terms of Cronbach's alpha than other constructs. Moreover, items in the construct assessment and relationship with students were defined as being good. These findings suggest that the instrument has construct validity with respect to these constructs and so it can be used as an assessment tool by students to assess their lecturers. However, though the construct preparation was acceptable with Cronbach's alpha 0.783 , more items can be added to it to make it more reliable. The fact that SLE questionnaire generally has high reliability coefficient implies that the tool is consistent and reliable in measuring students' perceptions concerning their lecturers and how they handle the lectures. This, therefore, implies that the university can safely utilise this instrument for uniformity and reliability of their results. In addition, the rotated EFA results revealed that some of the items have been rearranged thus reducing the constructs from five to four.

\section{Recommendations}

Based on the findings of this study, the researchers recommend the following:

- Lecturers in tertiary institutions may adopt this instrument as student-lecturer assessment tool during their lecturing practice;

- A training workshop should be organized for both parties in tertiary institutions on how to use the instrument to rate lecturers during the teaching practice;

The following are the suggested names of the new constructs of SLE questionnaire evaluated together with recommended additional items per construct:

- The lecturer's preparation, presentation and assessment

- Encourages students to prepare and read before a lecture

- Stays focused on the topic of discussion

- Comes to class regularly

- Manages time well for lectures

- Captures the attention of students

- Motivation and encouragement of students

- Creates friendly atmosphere during lectures

- Does not criticise students

- Treats all students fairly and with respects 
- Knowledge of course content

- Use different examples and scenarios to explain the topic/subject

○ Does not seem to struggle to clarify issues to students

- Relationship with students

- Engages students who are less outspoken in class

- Encourages critical thinking

- Responds constructively to students' opinions

Students should also be allowed to give general comments about the lecturer and the module facilitated.

\section{Acknowledgements}

The authors are thankful to the NWU for allowing them use the questionnaire and data for the success of this study and also for funding this paper.

\section{References}

Aiken, L.R. (2002). Attitudes and related psychosocial constructs: Theories, assessment and research. London: SAGE.

Alese, B.K., \& Owoyemi, S.O. (2004). Factor analytic approach to internet usage in South Western Nigeria. Journal of Information Technology Impact, 4(3), 171-188.

Alexander, C. (2008). Market risk analysis, quantitative methods in finance. England: John Wiley \& Sons.

Antony, M.M., \& Barlow D.H. (2011). Handbook of assessment and treatment planning for psychological disorders. New York: Guilford Press.

Auspitz, J.L. (1992). Praxiologies and the philosophy of economics. New Jersey: Transaction publishers.

Basow, S. A., Codos, S., \& Martin, J.L. (2013). The effects of professors' race and gender on student evaluations and performance. College Student Journal, 47(2), 352-363.

Blaha, J., Merydith, S.J., Wallbrown, F.H. \& Dowd, E.T. (2001). Bringing another perspective to bear on the factor structure of the MMPI2. Measurement and Evaluation in Counselling and Development, 33, 234-243.

Blank, R. (2004). The Basics of Reliability. New York: Productivity Press.

Brown, T.A. (2006). Confirmatory factor analysis for applied research: Methodology in the social sciences. New York: Guilford Press.

Bryant, F. B., \& Yarnold, P.R. (1995). Principal components analysis and exploratory and confirmatory factor analysis. Reading and understanding Multivariate Statistics. Washington D.C: American Psychological Association.

Bryson, C.P. (2007). Observed and self-reported childrearing in mothers with a history of sexual abuse. ProQuest.

Byrne, B. M., Shavelson, R. J., \& Muthén, B. (1989). Testing for the equivalence of factor covariance and mean structures. The issue of partial measurement invariance. Psychological Bulletin, 105(3), 456-466.

Coffey, D.Y. (2006). A Structural validity study of the adjustment scales for children and adolescents - home (ASCA-H). ProQuest.

Cohen, E. (2005). 'Student evaluations of course and teacher: factor analysis and SSA approaches. Assessment and evaluation in higher education'. 30(2), 123-136.

Comrey, A.L., \& Lee H.B. (1992). A First Course in Factor Analysis. Hillsdale, New Jersey: Erlbaum.

Costello, A.B. \& Osborne J.W. (2005). Best Practices in Exploratory Factor Analysis. Four Recommendations for Getting the Most from Your Analysis. Practical Assessment Research and Evaluation 10(7).

Coussement, K., Demoulin, N., \& Charry, C. (2011). Marketing Research with SAS Enterprise Guide. England: Gower Publishing, Ltd.

Crites, L.T. (2009). Four core principles for enhancing ministry effectiveness: A factor analysis evaluating the relationship between select variables and church health observed in churches of the Georgia Baptist Convention. : ProQuest.

Cronbach, L. J., \& Shavelson, R. J. (2004). My current thoughts on coefficient alpha and successor procedures. Educational and Psychological Measurement, 64, 391-218.

Diamantopoulos, A., \& Siguaw, J.A. (2006). Formative versus Reflective Indicators in Organizational Measure Development: A Comparison and empirical illustration. British Journal of Management, 17(4), 263-282.

Fabrigar, L.R., \& Wegener, D.T. (2012). Exploratory factor analysis: Series in understanding statistics. New York: Oxford University Press.

Field, A. (2013). Discovering Statistics using IBM SPSS Statistics. London: SAGE.

Frank, I.E., \& Todeschini, R. (1994). The data analysis handbook: Data handling in science and technology. Arnsterdam. Elsevier.

Frontiers E-books, (2013). Sweating the Small Stuff: Does data cleaning and testing of assumptions really matter in the 21st century? Frontiers E-books.

Furr, R.M. (2011). Scale Construction and Psychometrics for Social and Personality Psychology: The SAGE Library of Methods in Social and Personality Psychology. London: SAGE.

Glynn, M.S., \& Woodside, A.G. (2009). Business-to-business Brand Management: Theory, Research and Executive Case Study Exercises. Bingley: Emerald Group Publishing.

Hardy, M.A., \& Bryman, A. (2009). Handbook of Data Analysis. London: SAGE. 
Hatcher L. (2003). Step-By-Step Basic Statistics Using SAS(R): Exercises, Volume 2. SAS institute.

Hinkin, T.R. (2009). Research in Organizations c.21. Berrett-Koehler Publishers.

Hutcheson, G.D., \& Sofroniou, N. (1999). The Multivariate Social Scientist: Introductory Statistics Using Generalized Linear Models. London: SAGE.

Johnson, M., Narayanan, A., \& Sawaya, W., (2013). Effects of course and instructor characteristics on student evaluation of teaching across a college of engineering. Journal of Engineering Education, 102(2), 289-318.

Johnson, R.A., \& Witchen, D.W. (2007). Applied multivariate statistical analysis. Upper Saddle River Upper Saddle River, NJ: Pearson Prentice Hall.

Kim, M., \& Mallory, C. (2013). Statistics for evidence-based practice in nursing. Barlington, MA: Jones \& Bartlett Publishers.

Lago, R.M. (2007). Examining the psychometrics of number sense among kindergarten students. : ProQuest.

Leach, R.A. (2004). The chiropractic theories: A textbook of scientific research. Baltimore: Lippincott Williams \& Wilkins.

Leech, N., Barrett, K., \& Morgan, G.A. (2007). SPSS for intermediate statistics: Use and interpretation, $3^{\text {rd }}$ ed. New York. Routledge.

Lewis-Beck, M.S., Bryman, A.E., \& Liao, T.F. (2004). The SAGE Encyclopedia of Social Science Research Methods. New Yolk: SAGE.

LittleT.D. (2013). Longitudinal Structural Equation Modelling: Methodology in the Social Sciences. New Yolk: Guilford Publications.

Madichie, N. O. (2011). Students' evaluation of teaching (SLE) in higher education: A question of reliability and validity. Marketing Review, 11(4), 381-391.

Marcoulides, G.A. (2009). Modern methods for business research: Quantitative methodology series. (2nd ed). New Jersey: Psychology Press.

Marques de Sá J.P. (2007). Applied Statistics Using SPSS, STATISTICA, MATLAB and R: Using SPSS, Statistica, MATLAB, and R. (2nd e.d). Porto: Springer.

Marsh, H. W., \& Dunkin, M. J. (1997). Students' evaluations of university teaching: A multidimensional perspective. New York: Agathon.

Martínez-Gómez, Sierra, J., Jabaloyes, J. \& Zarzo, M. (2011). A multivariate method for analyzing and improving the use of student evaluation of teaching questionnaires: A case study. Quality and Quantity, 6, 1415-1427.

Marusish, M.E. (2004). Use of psychological testing for treatment planning and outcome assessment. Routledge.

Matignon, R. (2007). Data mining using SAS Enterprise Miner. New Jersey: John Wiley \& Sons.

McCoach, D.B., Gable, R.K., \& Madura J.P. (2013). Instrument development in the affective domain: School and Corporate Applications: Springer.

Munro, B.H. (2005). Statistical methods for health care research, statistical methods for health care research. (5 $5^{\text {th }}$ ed.). Lippincott: Williams \& Wilkins.

Ord, K. (2013). Principles of business forecasting, (1st ed).: Cengage Learning.

Pasch, J.R. (2008). Organizational commitment in a technology-focused organization. An investigation of military, government service, and contracted personnel. ProQuest.

Petscher, Y., Schatschneider, C., \& Compton, D.L. (2013). Applied Quantitative Analysis in the Social Sciences. New York: Routledge.

Pett, M.A., Lackey, N.R \& Sullivan J.J. (2003). Making Sense of Factor Analysis: The use of Factor Analysis for Instrument Development in Health Care Research. California. SAGE.

Pounder, J.S. (2007). Is Student Evaluation of Teaching Worthwhile? An Analytical Framework for Answering the Question. Quality Assurance in Education. An International Perspective, 15(2), 178-191.

Quinn, G.P., \& Keough, M.J. (2002). Experimental Design and Data Analysis for Biologists. : Cambridge University Press.

Rao, C.R., \& Sinharay, S. (2006). Handbook of Statistics. Psychometrics. Oxford: Elsevier.

Ratray, J., \& Jones M.C. (2005). Essential elements of questionnaire design and development: Journal of Clinical Nursing, 16, $234-243$.

Rencher, A. (2002). Methods of multivariate analysis. New York. Wiley \& Sons.

Rencher, A.C. (2003). Methods of multivariate analysis. Probability and Statistics. (2nd ed.). New Yolk: John Wiley and Sons.

Rietveld, T., \& Van Hout, R. (1993). Statistical techniques for the study of language and language behaviour. Berlin-New Yolk: Mouton de Groute.

Rummel, R.J. (1988). Applied Factor Analysis. Northwestern University Press.

Sahin, S., \& Yilmaz, H. (2011). A confirmatory factor analysis of the teaching and learning conceptions questionnaire (TLCQ). Journal of Instructional Psychology, 38(3/4), 194-200.

SAS/IML Studio 3.3. User's Guide (2010). North California: SAS Publishing.

Schmitt, T. A. (2011). Current methodological considerations in exploratory and confirmatory factor analysis. Journal of Psychoeducational Assessment, 29(4), 304-321.

Schinker, J.A \& Velicer, W.F. (2012). Handbook of Psychology, Research Methods in Psychology. New Jersey. John Wiley \& Sons.

Shevlin M., Banyard P., Davies M \& Griffiths M. (2000). The validity of student evaluation of teaching in higher education. Love me; love my lectures, Assessment and Evaluation in Higher Education, 25:4, 397-405, DOI: 10.1080/713611436.

Sok-Foon, Y., Sze-Yin, J., \& Yin-Fah, B. (2012). Student evaluation of lecturer performance among private university students. Canadian Social Science, (4), 238.

Stevens J.P. (2002). Applied Multivariate Statistics for the Social Sciences. (4th ed). Taylor and Francis.

Stevens, J. (1992). Applied Multivariate Statistics for the Social Sciences (2nd ed.). Hillsdale: Lawrence Erlbaum Ass.

Suhr, D.D. (2009). Principal component analysis versus explain factor analysis. Statistics and data analysis, 30, 203-230.

Supino, P.G., \& Borer, J.S. (2012). Principles of Research Methodology. A Guide for Clinical Investigators. Springer.

Tabachnick, B.G., \& Fidell, L.S. (2007). Using Multivariate Statistics, (5th ed.). Pearson Allyn and Bacon, Upper Saddle River: New 
Jersey.

Tabachnick, B.G., \& Fidell, L.S. (2012). Using Multivariate Statistics, (6 $6^{\text {th }}$ ed) Pearson Education, Limited.

Tam, C.M. (2007). Decision Making and Operations Research Techniques for Construction Management. Hong Kong. City University of HK Press.

Thompson, B. \& Daniel, L. G. (1996) Factor Analytic Evidence for the Construct Validity of Scores: A Historical Overview and Some Guidelines. Educational and Psychological Measurement, 56, 2, 197-208.

Warner, R.M. (2012). Applied statistics from bivariate through multivariate techniques. SAGE.

Watts, S., \& Stanner, P. (2007). Doing Q methodological research, theory, method and interpretation. London: SAGE.

Weiner, I.V., Schinka, A.J., \& Velicer, W.F. (2012). Handbook of Psychology, Research Methods in Psychology. (2nd ed.). Hoboken-New Jersey: John Wiley \& Sons.

Weisburd, D., \& Britt C. (2007). Statistics in criminal justice. New Yolk. Springer.

Woodsworth, A., \& Penniman, D.W. (2002). Contexts for the assessment and outcome evaluation in librarianship. Bingley. Emerald Group Publishing.

Zerihun, Z., Beishuizen, J., \& Van Os, W. (2012). Student learning experience as indicator of teaching quality. Educational Assessment, Evaluation and Accountability, 24(2), 99-111.

Zwick, W.R., \& Velicer, W. F. (1986). Factor influencing five rules for determining the number of components to retain, Psychological Bulletin, 99, 432-442.

Appendix: NWU SLE questionnaire

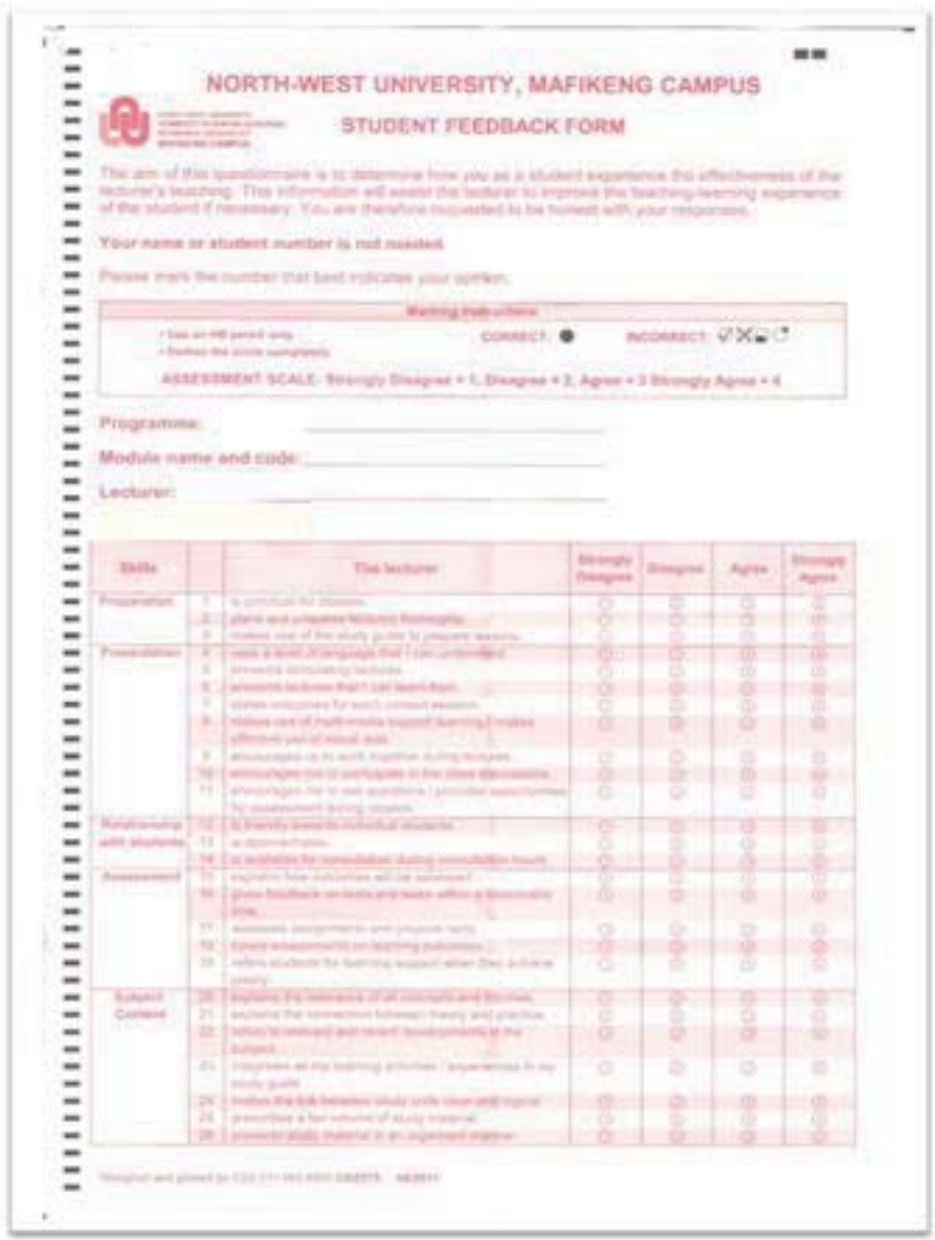

